\section{CLINICAL, MRI AND ARTHROSCOPIC CORRELATION OF MENISCAL AND ANTERIOR CRUCIATE LIGAMENT INJURIES OF THE KNEE}

\section{Original Article Orthopaedics}

Keshav Shenoy $\mathbf{S}^{1}$, Santosh S Jeevannavar², Prasanna Baindoor ${ }^{3}$

1 - Associate Professor, Department of Orthopaedics, SDM college of Medical Sciences and Hospital, Sattur, Dharwad.

2 - Professor, Department of Orthopaedics, SDM college of Medical Sciences and Hospital, Sattur, Dharwad. ${ }^{3}$ - Associate Professor, Department of Orthopaedics, SDM college of Medical Sciences and Hospital, Sattur, Dharwad.

Corresponding Author

Santosh S. Jeevannavar Professor, Department of Orthopaedics, SDM college of Medical Sciences and Hospital,

Sattur, Dharwad. 580009. Email-drssj99@gmail.com Mobile- 9845549427

\begin{abstract}
Background: Internal derangement of knee can pose diagnostic challenges to the orthopaedic surgeon, especially in acute settings. Clinical tests like McMurray test can be unreliable in the detection of meniscal tears. MRI is an investigative tool with high sensitivity and specificity for the diagnosis of ligamentous injuries of the knee. However, it is expensive. Arthroscopy can confirm the diagnosis but has associated surgical risks.
\end{abstract}

Materials and methods: 56 patients with ligamentous injuries of the knee, satisfying our inclusion criteria, were evaluated by clinical examination, MRI and arthroscopy. The results were analysed statistically (accuracy, sensitivity, specificity, positive predictive value and negative predictive value) to find a correlation among the three modalities.

Results: $>85 \%$ accuracy was noted while correlating clinical examination, $\mathrm{MRI}$ and arthroscopy for $\mathrm{ACL}$ injuries and lateral meniscal tears. The accuracy rates dropped to $55 \%$ for medial meniscal tears.

Conclusion: There is high degree of correlation when clinical examination is compared with $\mathrm{MRI}$ and arthroscopy for $\mathrm{ACL}$ tears and lateral meniscal tears. There is a low correlation between clinical findings in medial meniscal tears and MRI and arthroscopy findings of the same. Tests for medial meniscus can be false-positive in patients with Osteochondral defects of medial side of the knee.
Keywords: Arthroscopy, Magnetic Resonance Imaging, Meniscus 


\section{Introduction}

The incidence of ligamentous injuries of knee is increasing steadily due to an increase in road traffic accidents and increased participation in contact sports. Injury to any of these supporting structures leads to alteration in the overall motion of the knee, leading to knee instability ${ }^{1}$. Each specific knee injury has its own mechanism of occurrence and underlying risk factors. Injuries to ACL usually occur when the coefficient of friction between the athlete's foot and the playing surface increases, whereas meniscal injuries occur due to rotation stresses ${ }^{2}$.

A detailed history and a thorough clinical examination are crucial in the diagnosis of ligamentous injuries of the knee. However, clinical examination may be inaccurate and inconclusive in many cases, especially with meniscal injuries ${ }^{3,4}$. Clinical tests like the McMurray test for meniscus is reported to be positive in only $58 \%$ of the cases and a negative McMurray test does not rule out a meniscal tear ${ }^{5}$. Also, the clinical examination is subject to inter observer variations.

Diagnostic arthroscopy is regarded as the gold standard in the diagnosis of ACL and meniscal injuries ${ }^{6}$. However, it is associated with complications like infection, need for anesthesia etc.MRI is a sensitive (90-98\%) and specific $(90-100 \%)$ imaging method for the diagnosis of ACL injuries? The sensitivity of MRI is superior to clinical examination and also more specific than diagnostic arthroscopy ${ }^{8}$.

We performed a prospective study to find a correlation between clinical examination, MRI and arthroscopic findings in meniscal and ACL injuries in our institute.

\section{Materials And Methods}

The prospective study was performed between June 2016 and June 2018 in Shree Dharmasthala Manjunatheshwara College of Medical Sciences and Hospital, Dharwad. All the patients admitted in our institution, who were scheduled to undergo arthroscopic surgery of the knee for either meniscal injuries or ACL injuries and who satisfied our inclusion criteria, were included in the study.

The inclusion criteria were

1) Patients aged between 18 years- 60 years

2) Posted for arthroscopic surgery for meniscal injuries or ACL injuries based on clinical examination and MRI findings.

3) Time interval between MRI and arthroscopy being not more than 1 month, with no history of fresh injury in the interval period.

The exclusion criteria were

1) Patients aged $<18$ years or $>60$ years

2) Patients undergoing arthroscopy for ACL and meniscal injuries without MRI.

3) Arthroscopy done for other indications

4) Patients with associated collateral ligaments or PCL injuries.

56 patients, who satisfied the inclusion criteria, were enrolled in the study. Most of these patients were aged between 20 years- 30 years (Table No.1). Road traffic accident and selffall were the most common modes of injury (Table No.2). Knee pain was the most common symptom (Table No.3).
Table No. 1. Age distribution

\begin{tabular}{|l|c|c|}
\hline Age Group & $\begin{array}{c}\text { No. Of } \\
\text { Patients }\end{array}$ & Percentage \\
\hline$<20$ Years & 4 & $7.1 \%$ \\
\hline $21-30$ Years & 22 & $39.3 \%$ \\
\hline 31-40 Years & 14 & $25 \%$ \\
\hline 41-50 Years & 12 & $21.4 \%$ \\
\hline 51-60 Years & 4 & $7.1 \%$ \\
\hline
\end{tabular}

Table No. 2. Mode of injury

\begin{tabular}{|l|c|c|}
\hline $\begin{array}{c}\text { Type Of } \\
\text { Injury }\end{array}$ & $\begin{array}{c}\text { No. Of } \\
\text { Patients }\end{array}$ & Percentage \\
\hline $\begin{array}{l}\text { Road } \\
\text { Traffic } \\
\text { Accident }\end{array}$ & 16 & $28.6 \%$ \\
\hline Self-Fall & 16 & $28.6 \%$ \\
\hline $\begin{array}{l}\text { Sports } \\
\text { Injury }\end{array}$ & 11 & $19.6 \%$ \\
\hline Others & 13 & $23.2 \%$ \\
\hline
\end{tabular}

Each patient was clinically examined in detail by an experienced orthopedic surgeon and the examination findings were documented in separate case sheets. A detailed history was elicited and a clinical examination was performed. The clinical findings like medial and lateral joint line tenderness, effusion and range of motion were noted. The ligaments were assessed by performing the special tests. Anterior drawer test and Lachman's test were done to detect ACL injury. The meniscal injuries were detected by McMurray test and Apley's grinding test. Posterior drawer test was performed to rule out PCL injury and Dial test was done to rule out injuries of the posterolateral corner of knee. The medial and the lateral collaterals were assessed with valgus and varus stress tests.

Table No. 3. Presenting symptom

\begin{tabular}{|l|c|c|}
\hline Symptoms & $\begin{array}{c}\text { No. Of } \\
\text { Patients }\end{array}$ & Percentage \\
\hline Knee Pain & 29 & $51.8 \%$ \\
\hline $\begin{array}{l}\text { Knee Pain } \\
\text { \& Swelling }\end{array}$ & 12 & $21.4 \%$ \\
\hline $\begin{array}{l}\text { Knee } \\
\text { Pain \& } \\
\text { Instability }\end{array}$ & 07 & $12.5 \%$ \\
\hline
\end{tabular}




\begin{tabular}{|l|c|c|}
\hline $\begin{array}{l}\text { Knee Pain } \\
\text { \& Locking }\end{array}$ & 05 & $8.9 \%$ \\
\hline Instability & 02 & $3.6 \%$ \\
\hline $\begin{array}{l}\text { Knee Pain, } \\
\text { Swelling, }\end{array}$ & 01 & $1.8 \%$ \\
$\begin{array}{l}\text { Locking \& } \\
\text { Instability }\end{array}$ & & \\
\hline
\end{tabular}

The patients then underwent MRI scan (1.5 Tesla machine). The protocol for imaging the knee included was multiplanar with following sequences.

(a) Localizer sequences in sagittal, coronal and axial planes

(b) Fat suppressed T2 axial Turbo spin echo

(c) Short Tau inversion recovery (STIR) coronal

(d) Proton density (PD) and T2 turbo spin echo sagittal

(e) Proton density (PD) and T2 turbo spin echo coronal

(f) T1 spin echo sagittal.

The images were reported by a single experienced radiologist.

Arthroscopic surgery was performed within a month after MRI evaluation. The arthroscopy was done by an experienced orthopedic surgeon. The surgeries were performed under spinal or general anaesthesia. A thorough examination under anesthesia (EUA) was done prior to arthroscopy and Pivot shift test was done to detect ACL injury. The sequence of arthroscopic examination was:

1. Suprapatellar pouch and patellofemoral joint

2. Medial gutter

3. Medial compartment

4. Intercondylar notch

5. Posteromedial compartment

6. Lateral compartment

7. Lateral gutter and posterolateral compartment

After performing a thorough arthroscopy of the knee, the injured structure was identified and treated accordingly. The arthroscopic findings were recorded in detail in the operative notes.

\section{Results}

Statistical analysis was used to calculate sensitivity, specificity, positive predictive value (PPV) and negative predictive value (NPV), accuracy in order to assess the reliability of the Arthroscopy and MRI results. To evaluate the sensitivity, specificity and accuracy of MRI, the findings at arthroscopy were taken to be the true diagnosis.

Sensitivity was calculated from the number of true positive results divided by the sum of the true positive results and the false negative results.

Specificity was calculated from the number of true negative results divided by the sum of the true negative results and the false positive results.

Positive predictive value was calculated by true positive divided by sum of true and false positive results multiplied by 100 .

Negative predictive value was calculated by true negative divided by sum of true and false negative results multiplied by 100 .

Accuracy was calculated from the sum of the true positive and the true negative results divided by the total number of patients who underwent arthroscopy. The data was analysed using SPSS 17.26 version. The following were the results of the study.

\section{Arthroscopic findings}

Longitudinal tears were the most common type of medial meniscal tears seen followed by bucket handle tears.Longitudinal tears were the most common type of lateral meniscal tear followed by radial tears.

Isolated ACL tears were seen in 4 patients, ACL + Medial Meniscus tears were seen in 4 patients, isolated
Medial Meniscus tears were seen in 13 patients and isolated Lateral Meniscus tears were seen in 06 patients. Osteochondral defects were noted in 17 patients.

\section{1) Correlation of Clinical} Examination with Arthroscopic Examination of Medial Meniscal tears:

The Sensitivity was $72 \%$, Specificity was $42 \%$, Positive Predictive Value was $50 \%$, Negative Predictive value was $65 \%$ and Accuracy was 55\% (Table No.4).

Table No. 4

\begin{tabular}{|l|c|c|c|}
\hline $\begin{array}{c}\text { Clinical } \\
\text { Examination }\end{array}$ & \multicolumn{2}{|c|}{$\begin{array}{c}\text { Tear } \\
\text { Present On } \\
\text { Arthroscopy }\end{array}$} & \\
\hline & Yes & No & Total \\
\hline Positive & 18 & 18 & 36 \\
\hline Negative & 07 & 13 & 20 \\
\hline
\end{tabular}

2) Correlation of MRI findings with Arthroscopic Examination of Medial Meniscal tears:

The Sensitivity was $92 \%$, Specificity was $77 \%$, Positive Predictive Value was $76.7 \%$, Negative Predictive value was $92.3 \%$ and Accuracy was $83 \%$ (Table No.5).

Table No. 5

\begin{tabular}{|l|c|c|c|}
\hline $\begin{array}{c}\text { Clinical } \\
\text { Examination }\end{array}$ & \multicolumn{2}{|c|}{$\begin{array}{c}\text { Tear } \\
\text { Present On } \\
\text { Arthroscopy }\end{array}$} & \\
\hline & Yes & No & Total \\
\hline Positive & 23 & 07 & 30 \\
\hline Negative & 02 & 24 & 26 \\
\hline
\end{tabular}

3) Correlation of Clinical Examination with Arthroscopic Examination of Lateral Meniscal tears: (Table No. 6)

Table no.6

\begin{tabular}{|l|c|c|c|}
\hline $\begin{array}{c}\text { Clinical } \\
\text { Examination }\end{array}$ & \multicolumn{2}{|c|}{$\begin{array}{c}\text { Tear } \\
\text { Present On } \\
\text { Arthroscopy }\end{array}$} & \\
\hline & Yes & No & Total \\
\hline Positive & 08 & 00 & 08 \\
\hline Negative & 02 & 46 & 48 \\
\hline
\end{tabular}


The Sensitivity was $80 \%$, Specificity was $100 \%$, Positive Predictive Value was $100 \%$, Negative Predictive value was $95.83 \%$ and Accuracy was 95\% (Table No.6).

4) Correlation of MRI findings with Arthroscopic Examination of Lateral Meniscal tears: (Table No. 7)

Table No. 7

\begin{tabular}{|l|c|c|c|}
\hline $\begin{array}{c}\text { Clinical } \\
\text { Examination }\end{array}$ & \multicolumn{2}{|c|}{$\begin{array}{c}\text { Tear } \\
\text { Present On } \\
\text { Arthroscopy }\end{array}$} & \\
\hline & Yes & No & Total \\
\hline Positive & 09 & 00 & 09 \\
\hline Negative & 01 & 46 & 47 \\
\hline
\end{tabular}

The Sensitivity was 90\%, Specificity was $100 \%$, Positive Predictive Value was $100 \%$, Negative Predictive value was $97.9 \%$ and Accuracy was 98\% (Table No.7).
5) Comparison of Clinical Examination with Arthroscopic Examination of ACL tears: (Table No. 8)

Table No. 8

\begin{tabular}{|l|c|c|c|}
\hline $\begin{array}{c}\text { Clinical } \\
\text { Examination }\end{array}$ & \multicolumn{2}{|c|}{$\begin{array}{c}\text { Tear } \\
\text { Present On } \\
\text { Arthroscopy }\end{array}$} & \\
\hline & Yes & No & Total \\
\hline Positive & 11 & 04 & 15 \\
\hline Negative & 04 & 37 & 41 \\
\hline
\end{tabular}

The Sensitivity was $73.3 \%$, Specificity was $90.2 \%$, Positive Predictive Value was $73.3 \%$, Negative Predictive value was $90.2 \%$ and Accuracy was $86 \%$ (Table No.8).

6) Correlation of MRI findings with Arthroscopic Examination of ACL tears:

The Sensitivity was $80 \%$, Specificity was $92 \%$, Positive Predictive Value was $80 \%$, Negative
Predictive value was $92.68 \%$ and Accuracy was $89 \%$ (Table No.9).

Table No. 9

\begin{tabular}{|l|c|c|c|}
\hline $\begin{array}{c}\text { Clinical } \\
\text { Examination }\end{array}$ & \multicolumn{2}{|c|}{$\begin{array}{c}\text { Tear } \\
\text { Present On } \\
\text { Arthroscopy }\end{array}$} & \\
\hline & Yes & No & Total \\
\hline Positive & 12 & 03 & 15 \\
\hline Negative & 15 & 41 & 56 \\
\hline
\end{tabular}

7) Correlation for a particular type of lesion in all three aspects (Clinical Examination, MRI, Arthroscopic Examination).

Correlation in all three aspects was $72 \%$ for medial meniscal tears, $80 \%$ for lateral meniscus and $73.3 \%$ for ACL tears.

8) Comparison of Clinical Examination for ACL, Medial Meniscus and Lateral Meniscus (Table No. 10):

Table No.10

\begin{tabular}{|l|c|c|c|c|c|}
\hline Results & Accuracy & Sensitivity & Specificity & Ppv & Npv \\
\hline Acl & $86 \%$ & $73.5 \%$ & $90.2 \%$ & $73.3 \%$ & $90.2 \%$ \\
\hline $\begin{array}{l}\text { Medial } \\
\text { Meniscus }\end{array}$ & $55 \%$ & $72 \%$ & $42 \%$ & $50 \%$ & $65 \%$ \\
\hline $\begin{array}{l}\text { Lateral } \\
\text { Meniscus }\end{array}$ & $95 \%$ & $80 \%$ & $100 \%$ & $100 \%$ & $95.83 \%$ \\
\hline
\end{tabular}

9) Comparison of MRI findings for ACL, Medial Meniscus and Lateral Meniscus (Table No. 11):

Table No. 11

\begin{tabular}{|l|c|c|c|c|c|}
\hline Results & Accuracy & Sensitivity & Specificity & Ppv & Npv \\
\hline Acl & $89 \%$ & $80 \%$ & $92.7 \%$ & $80 \%$ & $92.7 \%$ \\
\hline $\begin{array}{l}\text { Medial } \\
\text { Meniscus }\end{array}$ & $83 \%$ & $92 \%$ & $77.1 \%$ & $76.7 \%$ & $92.3 \%$ \\
\hline $\begin{array}{l}\text { Lateral } \\
\text { Meniscus }\end{array}$ & $98 \%$ & $90 \%$ & $100 \%$ & $100 \%$ & $97.9 \%$ \\
\hline
\end{tabular}

\section{Discussion}

In the past, the ligamentous injuries of the knee were primarily diagnosed on detailed clinical examination, as radiographs alone were inadequate to diagnose them. Clinical examination alone, even in experienced hands, produced false diagnosis rates ranging between $\quad 40 \%-85 \%$, especially for meniscal injuries ${ }^{3,4}$. Clinical examination is also subject to inter observer variations.

Subsequently, many studies were performed evaluating the efficacy of combination of clinical examination and diagnostic arthroscopy in the diagnosis of meniscal and ACL injuries. DeHaven et al, reported a very high incidence of ACL tears and meniscal injuries in patients with acute traumatic hemarthrosis in whom arthroscopy was done as a diagnostic procedure9. Johnson LL et al, compared clinical examination and diagnostic arthroscopy, and found a significant number of additional diagnoses, including some which were 
completely different from the clinical diagnosis ${ }^{10}$. Curran et al studied 396 knee arthroscopies and found that the total clinical accuracy rate was only $71 \%$. Diagnostic arthroscopy increased their accuracy rates to $97 \%{ }^{11}$.

MRI of the knee has become a reliable tool in the detection of knee injuries and is the preferred investigative modality today. It is noninvasive, and allows the evaluation of all the soft tissues and bony structures, including the articular cartilage. The sensitivity and specificity of MRI in the diagnosis of ligamentous injuries is more than $90 \%{ }^{7,8}$.

A review of literature suggests a good correlation for ACL injuries diagnosed clinically and then evaluated by MRI and arthroscopy. However, when evaluating clinically suspected meniscal injuries, there is less correlation between clinical examination and MRI and arthroscopy. We compared our study with previous similar studies done. Rayan ${ }^{12}$ et al performed a similar study on 131 patients. While correlating clinical examination with arthroscopic finding of medial meniscal tear they found an accuracy of $79 \%$, sensitivity of $86 \%$, specificity of $73 \%$, positive predictive value of $76 \%$ and negative predictive value of $83 \%$. The correlation of clinical examination with MRI and arthroscopy for ACL tears were much higher, with accuracy being $93 \%$, sensitivity $77 \%$, specificity $100 \%$, positive predictive value $100 \%$ and negative predictive value $95 \%$.

Similar studies done by other authors like Navaliet $\mathrm{al}^{13}$, Nikolaou et $\mathrm{al}^{14}$, Loo WH et $\mathrm{al}^{15}$ have yielded similar results while correlating clinical examination with MRI and arthroscopy in the diagnosis of ligamentous injuries of the knee.

The accuracy of clinical examination for medial meniscus in our study is less than that found in other studies $(50 \%)$. This can be explained by the fact that many of our cases in which tests for medial meniscus were positive had an Osteochondral defect on arthroscopy. All the patients in our study underwent MRI evaluation in a 1.5 Tesla machine with no special sequences for articular cartilage imaging. Hence, these defects were missed in the MRI image.

The results of our study are comparable to other studies for ACL and lateral meniscal injuries. Hence, a patient diagnosed clinically with either an ACL injury or lateral meniscal injury can be counselled for definitive management of these injuries with greater degree of confidence, relying solely on clinical examination. However, it has become a standard practice to do MRI pre-operatively before subjecting the patient for surgery.

\section{Conclusion}

We would like to arrive at these conclusions from our study

1) Clinical tests to detect ACL and lateral meniscal injuries have a high degree of correlation when compared with MRI and arthroscopy.

2) Clinical tests to detect medial meniscal tears have a low degree of correlation when compared with MRI and arthroscopy.

3) Clinical tests done to detect medial meniscal injuries can be false positive for Osteochondral defects of the medial compartment of the knee.

4) When treating medial meniscal tears, the surgeon should be prepared to treat unsuspected
Osteochondral defects found at arthroscopy, especially when no MRI or a sub-optimal MRI has been done.

\section{References}

1. Woo SL, Debski RE, Withrow JD, Janaushek MA. Biomechanics of knee ligaments.Am JSports Med. 1999 Jul-Aug; 27(4): 533-43.

2. Powell JW, Schootman M. A multivariate risk analysis of selected playing surfaces in the National Football League: 1980 to 1989. An epidemiologic study of knee injuries.Am J SportsMed. 1992 Nov-Dec; 20(6): 686-94.

3. Miller GK. A prospective study comparing the accuracy of the clinical diagnosis of meniscal tears with magnetic resonance imaging and its effect on clinical outcome. Arthroscopy. 1996 Aug; 12(4): 406-13.

4. Gillies H, Seligson D. Precision in the diagnosis of meniscal lesions: a comparison of clinical evaluation, arthrography and arthroscopy. J Bone Joint Surg Am. 1979 Apr; 61(3): 343-6.

5. Anderson AF, Lipscomb AB. Clinical diagnosis of meniscal tears. Description of a new manipulative test.Am J Sports Med. 1986 Jul-Aug; 14(4): 291-3.

6. Crawford R, Walley G, Bridgman $S$, Maffulli N. Magnetic resonance imaging versus arthroscopy in the diagnosis of knee pathology, concentrating on meniscal lesions and ACL tears: a systematic review. Br Med Bull. 2007; 84:5-23.

7. Fitzgerald SW, Remer EM, Friedman H, Rogers LF, Hendrix RW, Schafer MF. MR evaluation of the anterior cruciate ligament: value of supplementing sagittal images with coronal and axial images. 
AJR Am J Roentgenol. 1993 Jun; 160(6): 1233-7.

8. Lee JK, Yao L, Phelps CT, Wirth CR, Czajka J, Lozman J. Anterior cruciate ligament tears: MR imaging compared with arthroscopy and clinical tests. Radiology. 1988 Mar; 166(3): 861-4.

9. DeHaven KE, Collins HR. Diagnosis of internal derangements of the knee. The role of arthroscopy.J Bone Joint Surg Am.1975 Sep; 57(6): 802-10.

10. Johnson LL. Comprehensive Arthroscopic Examination of the Knee. St Louis; CV Mosby 1977: 50-53.
11. Curran WP Jr, Woodward EP. Arthroscopy: its role in diagnosis and treatment of athletic knee injuries. Am J Sports Med. 1980 Nov-Dec; 8(6): 415-8.

12. Rayan F, Bhonsle S, Shukla DD. Clinical, MRI and arthroscopic correlation in meniscal and anterior cruciate ligament injuries. Int Orthop. 2009 Feb; 33(1): 129-32.

13. Navali AM, Bazavar M, Mohseni MA, Safari B, Tabrizi A. Arthroscopic evaluation of the accuracy of clinical examination versus MRI in diagnosing meniscus tears and cruciate ligament ruptures. Arch Iran Med. 2013 Apr;
16(4): 229-32.

14. Nikolaou VS, Chronopoulos E, Savvidou C, Plessas S, Giannoudis $\mathrm{P}$, Efstathopoulos N, Papachristou G. MRI efficacy in diagnosing internal lesions of the knee: a retrospective analysis. J Trauma Manag Outcomes. 2008 Jun 2;2(1):4.

15. Loo WH, Liu YB, Dave Lee YH, Micheal Soon YH. A Comparison of Accuracy between Clinical History, Physical Examination and Magnetic Resonance Imaging and Arthroscopy in the Diagnosis of Meniscal and Anterior Cruciate Ligament Tears.J Ortho. 2008; $5(3): 8$. 